\title{
Correction to: Criteria for assessing the quality of clinical practice guidelines in paediatrics and neonatology: a mixed-method study
}

Joanna Dagard ${ }^{1 *} \mathbb{0}$, Nadia Mazille-Orfanos ${ }^{1 *}$, Nawras Georgi ${ }^{2}$, Intissar Dechicha ${ }^{3}$, Guy Carrault ${ }^{2}$, Patrick Pladys ${ }^{1,2}$ and Alain Beuchée $e^{1,2}$

\section{Correction to: BMC Med Inform Decis Mak (2021) 21:269}

https://doi.org/10.1186/s12911-021-01628-1

Following publication of the original article [1], it was reported that the names of all authors were published with their given name and family name in reverse order. The correct authorship list is given in this Correction and the original article [1] has been updated.

\section{Publisher's Note}

Springer Nature remains neutral with regard to jurisdictional claims in published maps and institutional affiliations.

\section{Author details}

${ }^{1}$ Department of Pediatrics/Neonatology, CHU Rennes, 35033 Rennes, France.

${ }^{2}$ LTSI-UMR_S 1099, Univ Rennes, Inserm, 35000 Rennes, France. ${ }^{3}$ Paediatric

Department, Hospital of Fougères, Fougères, France.

Published online: 05 October 2021

\section{Reference}

1. Dagard J, Mazille-Orfanos N, Georgi N, et al. Criteria for assessing the quality of clinical practice guidelines in paediatrics and neonatology: a mixed-method study. BMC Med Inform Decis Mak. 2021;21:269. https:// doi.org/10.1186/s12911-021-01628-1. 